\section{CIENCIA Y NATURALEZA EN GOETHE: APUNTES SOBRE LA EPISTEMOLOGÍA NATURAL GOETHEANA A PARTIR DE LA METAMORFOSIS DE LAS PLANTAS}

Kilian Lavernia

Universidad Nacional de Educación a Distancia ORCID iD: https://orcid.org/0000-0002-8163-9636 klavernia@fsof.uned.es

Cómo citar este artículo/Citation: Lavernia, Kilian (2020). Ciencia y naturaleza en Goethe: apuntes sobre la epistemología natural goetheana a partir de La metamorfosis de las plantas. Arbor, 196 (798): a583. https://doi.org/10.3989/arbor.2020.798n4007

Recibido: 17 diciembre 2019. Aceptado: 10 agosto 2020.

RESUMEN: El artículo reactualiza y defiende la potencialidad filosófica de La metamorfosis de las plantas (1791), de Johann Wolfgang Goethe. A partir de la reflexión sobre sus claves conceptuales se desplegarán, a continuación, otros momentos de talante epistemológico relativos a su reflexión sobre la naturaleza, entre otros: la morfología como teoría de la forma, su comprensión de la ciencia como experiencia viva de los fenómenos y su reivindicación de la metamorfosis del científico.

PALABRAS CLAVE: Goethe; metamorfosis de las plantas; naturaleza; morfología; ciencia.
SCIENCE AND NATURE IN GOETHE: NOTES ON THE GOETHEAN NATURAL EPISTEMOLOGY IN HIS METAMORPHOSIS OF PLANTS

Copyright: (C) 2020 CSIC. Este es un artículo de acceso abierto distribuido bajo los términos de la licencia de uso y distribución Creative Commons Reconocimiento 4.0 Internacional (CC BY 4.0).
ABSTRACT: This paper updates and defends Goethe's Metamorphosis of Plants (1791) from a philosophical perspective. After presenting some of his key concepts, we will expand on Goethe's reflection on nature through other epistemological moments: his morphology as theory of form, his understanding of science as a living experience of phenomena, and his assertion of a metamorphosis of the scientist.

KEYWORDS: Goethe; metamorphosis of plants; nature; morphology; science. 
Como el linaje de las hojas, Tal es también el de los hombres. llíada, 6, 149

\section{INTRODUCCIÓN}

La originalidad y potencialidad teórica de las ideas científico-naturales de Johann Wolfgang Goethe continúa reclamando su rabiosa actualidad. En las últimas décadas, el agravamiento imparable de los problemas medioambientales y la cada vez más preocupante crisis ecológica que nos amenaza han favorecido una revalorización significativa, por parte de filósofos, biólogos e historiadores de la ciencia, de su contribución en relación a sus numerosos y muy diversos estudios sobre la naturaleza ${ }^{1}$. No es para menos. Alguien que ha llegado a declarar que «si el investigador de la naturaleza quiere afirmar su derecho a una contemplación y a un examen libres, entonces tiene que obligarse a garantizar los derechos de la naturaleza; sólo allí donde ella sea libre, él será libre; allí donde se la sujete con leyes humanas, también él será encadenado» (LA I, 8: 388), nos invita a releer sus indagaciones osteológicas, botánicas, ópticas, geológicas o meteorológicas con renovado interés ${ }^{2}$. Recogidas aún en vida, entre 1817 y 1824, bajo la rúbrica de los seis volúmenes de Zur Naturwissenschaft überhaupt, besonders zur Morphologie, todas aquellas investigaciones científicas configuran, junto a la Farbenlehre de 1810, un andamiaje textual de diferentes décadas, que es inseparable de su mirada como artista, pues arte y ciencia siempre fueron para Goethe dos estrategias simbólicas convergentes de expresar la naturaleza.

En lo que sigue, pues, nos detendremos en un momento cardinal de este camino formativo, y reflexionaremos, de manera concreta, sobre la potencialidad de La metamorfosis de las plantas, así como en los escritos de corte heurístico y epistemológico que complementan la temática de la morfología. En su reactualización se despliega una rica comprensión de la ciencia como experiencia viva de los fenómenos, en la que se pone en práctica un ideal cognoscitivo que exige de nosotros mayor reflexividad y apertura de horizontes con respecto a la interdimensionalidad constitutiva de la naturaleza. En este sentido, reevaluar dicha comprensión, al menos desde la mirada que pueda aportar un filósofo, puede resultar de provecho. Para ello desarrollaré gradualmente algunas estaciones de esta original aproximación. Primero expondré las ideas principales de La metamorfosis de las plantas, articuladas en torno a la definición posterior de la Urpflanze. A continuación, y sirviéndome también de otros textos de Goethe teóricamente convergentes con el ensayo botánico, intentaré definir los conceptos de morfología y de ciencia que se desprenden de la epistemología natural goetheana, reactualizando su posible valor crítico-filosófico para pensar, todavía hoy, el problema de la naturaleza. Como conclusión, terminaré con una reflexión sobre la reivindicación goetheana de la metamorfosis del científico respecto de la propia naturaleza.

\section{LA METAMORFOSIS DE LAS PLANTAS: DESCRIP- CIÓN Y HORIZONTE DE COMPRENSIÓN}

En el año 1790 aparece el escrito de Goethe titulado Ensayo para explicar la metamorfosis de las plantas (Versuch die Metamorphosen der Pflanzen zu erklären), una especie de balance de los estudios botánicos realizados durante su decisivo viaje formativo a Italia. La idea rectora que preside esta investigación es, en sus propias palabras, «el intento de explicar la metamorfosis de las plantas, es decir, de reconducir a un principio general simple la multiplicidad de los fenómenos particulares del espléndido jardín del mundo» (Goethe, 1997: 76). Partiendo de sus múltiples observaciones, descripciones y clasificaciones científicas, pero también desde el apoyo visual de los dibujos realizados durante aquel periplo, el escritor weimarés irrumpía en el campo botánico con una teoría de las plantas que mostraba su deuda con los grandes estudios de Linneo y su principio de la prolepsis, así como las teorías epigenéticas de Caspar Friedrich Wolff y las investigaciones coetáneas de Blumenbach ${ }^{3}$. En las distintas partes de un determinado tipo de planta anual dicotidelónea, Goethe veía el resultado de un proceso de transformación surgido en el crecimiento de la planta. En esta medida, pues, las visualizaba como modificaciones de un órgano fundamentalmente hipotético que, ya desde sus decisivas Notizen aus Italien iniciadas en el jardín botánico de Padua (LA II, 9A: 45-66), fija en un concepto más dinámico que estático de «hoja».

Ahora bien, Goethe no comprende la metamorfosis foliar en el sentido de que una misma hoja vaya tomando las formas de la planta como tal, sino que todos los órganos de la planta, desde las raíces hasta los estambres, desde el tallo hasta los frutos, serían solo formas transmutadas de tales hojas. En efecto, la metamorfosis no es observable como desarrollo unitario de la planta a partir de dicho órgano hipotético, pero sí intuible como desarrollo de posibilidades contenidas en este, movidas por impulsos formativos subyacentes que en cada instante configuran, en un espacio morfológico plural, variable y dinámico, sin centro ni 
finalidad predeterminados, las estructuras empíricas de la planta particular. De este modo, todo el desarrollo de la planta podría explicarse a partir de leyes estructurales de transformación que actúan según principios formativos del crecimiento y la reproducción específicos de los vegetales, atravesados siempre por el orden de polaridad e intensificación típicamente goetheano, encarnados aquí por las fuerzas de la dilatación (Ausdehnung) y la contracción (Zusammenziehung) alternantes:

La planta puede crecer, florecer o dar frutos, pero son siempre los mismos órganos los que, en destinos y formas con frecuencia diversa, siguen las prescripciones de la naturaleza. El mismo órgano que se expande en el tallo como hoja y toma las formas más diversas, se contrae luego en el cáliz, vuelve a expandirse en los pétalos, se contrae en los órganos reproductores, y se vuelve a expandir, por último, como fruto (Goethe, 1997: 71-72)4.

Así, desde la fisonomía de la semilla que germina hasta la planta que produce el fruto, esta última crecería modificando sus órganos de acuerdo con la oscilación entre tales impulsos de proliferación vegetal y concentración seminal, atestiguando así, de manera encarnada, aquellas fuerzas alternantes de su constancia epigenética que ninguna taxonomía podía barruntar.

En una anotación del 27 de septiembre de 1786, al inicio de su periplo italiano, encontramos el origen de esta primera intuición:

Aquí, en medio de esta nueva diversidad que se me ofrece, vuelve a cobrar cada vez mayor vida en mí esa idea de que quizá todas las formas vegetales se deriven de una sola. Sólo con arreglo a ese criterio sería posible determinar verdaderamente generaciones y variedades, lo que hasta ahora, a juicio mío, se ha hecho con harta arbitrariedad (Goethe, 1991: 1074).

He aquí la futura Urpflanze, la «planta primordial» in statu nascendi. Lejos de ser una idea abstracta, nos encontramos ante una realidad experimentada en un nivel más profundo, que unifica las estructuras cambiantes de la planta y permite al observador externo considerar cada estructura no como algo separado, sino como expresión múltiple de un órgano ideal. Se trata de un principio unificador sin uniformidad, que distingue sin dividir, y que se expresa a través de la especificidad de lo diverso, de los elementos formales espacialmente separados. Es algo que, en todo caso, se manifiesta y se vuelve visible al ojo humano a través del estudio activo de los diversos fenómenos de la vida inherente a la planta. Es un pensar que percibe, y un percibir que piensa, que revela simultáneamente lo particular y universal del proceso orgánico observado. En cierto modo, como señala Félix Duque, "la universalidad se halla empíricamente, singularmente encarnada. Tal es el caso de la Urpflanze: en lo sensible, dejar que brille lo suprasensible e ideal» (Duque, 2000: 101) .

Así que no puede decirse que la metamorfosis de las plantas sea ni un proceso puramente empírico, ni tampoco meramente abstracto, al consistir en las transformaciones producidas por una fuerza no observable ella misma de manera directa, pero cuyos efectos sí son perceptibles al observador. Por eso la legalidad que postula Goethe no es científica en sentido estricto, por mucho que respete heurísticamente la necesaria observación, clasificación y descripción del fenómeno vivo. La ley es más bien la relación estructural de la conexión de los fenómenos, considerados según su «entrega» o donación a la percepción humana, a través de la cual una forma se convierte en otra, actualizándose así en su concreción empírica, como relación viviente entre la idea de un fenómeno natural y su manifestación sensible. Una vez comprendido este poder de formación de la esencia, la Urpflanze nos permite percibir los estadios del crecimiento y la metamorfosis de la planta como distintas manifestaciones vivas de una única forma proteica ${ }^{6}$.

\section{UNA APROXIMACIÓN AL CONCEPTO DE MORFO- LOGÍA}

Llegamos así al segundo pilar de la epistemología natural de Goethe, a saber, la centralidad otorgada a la forma (Gestalt) y su comprensión de la naturaleza como un continuum de formas, por decirlo con Maatsch (2014: 2). De entrada, conviene establecer con meridiana claridad que, con su propuesta de una ciencia morfológica, que incluía también sus estudios osteológicos en la metamorfosis de los animales ${ }^{7}$, Goethe propuso fundar una nueva disciplina como teoría de la forma y de la formación de las naturalezas orgánicas: "La morfología», afirma, «debe contener la teoría de la forma, de la formación y de la transformación de los cuerpos orgánicos; pertenece, pues, a las ciencias naturales» (Goethe, 1997: 113) ${ }^{8}$.

La ciencia morfológica no estudia por tanto los seres naturales como cosas aisladas e individuales, sino como expresiones de su naturaleza que consiste, precisamente, en su incesante autoformarse como pluralidad. De hecho, el conocimiento de la fuerza inmanente a toda forma aspira a cierta fijación de su correspondiente movimiento, de su cambio y desarro- 
llo a lo largo del tiempo de la naturaleza, como cualitativamente distinto del tiempo humano, el tiempo de la cultura9 ${ }^{9}$ La forma es, en cierto modo, un medio de conocimiento, una parte de la producción de los objetos del mundo, porque toda captación de la misma, en cuanto figura delimitada e imagen (Bild), ofrece una información espacializada que permite unificar al mismo tiempo las informaciones objetivas y sensibles $y$ las propiedades de virtualidades ocultas, que se ofrecen así en su inteligibilidad.En todo caso, a través del método morfológico no se capta un proceso genético en el que un mismo órgano se transforma en todos los demás órganos. Antes bien, aplicando este método se descubre una afinidad morfológica de sus partes. Pues cuando observamos detenidamente las partes en sus relaciones y variaciones cualitativas, nos volvemos conscientes de la unidad de la vida cambiante de la planta. Nuestra atención se traslada de los productos a la fuente productiva de la vida en la planta, que es algo nunca fijo ni estático, sino más bien dinámico. "Para reconocer», sentencia Goethe, «[el hombre] debe separar lo que no debía ser separado; y aquí no hay otro medio que el de reunificar de nuevo lo que la naturaleza presenta a nuestro conocimiento separadamente, teniendo en cuenta cómo una forma se transforma insensiblemente en otra $y$, por último, es totalmente absorbida por la forma siguiente» (Goethe, 1997: 122).

Desde esta perspectiva, lo determinante de la morfología no es tanto el objeto de estudio, cuanto los procedimientos utilizados y las exigencias reflexivas que todo procedimiento experimental implica en el proceso cognoscitivo, empezando por los instrumentos priorizados en la propia observación:

a) La morfología no es explicativa, sino expositiva. Al considerar la naturaleza bajo la idea de inmanencia (organismo como causa y fin de sí mismo), la morfología no pretende dar razón del cambio de los seres vivos en términos de causas y efectos, ni interrogarlos respecto de su esencia o razones últimas. Antes bien, se limita a exponer tales cambios de manera clara y descriptivamente cuidadosa, de ahí la importancia nodal del lenguaje utilizado, de sus límites y potencialidades.

b) La morfología se basa en comparar diferentes observaciones de un mismo fenómeno visible, a fin de buscar y poner de manifiesto el fenómeno de su estructura orgánica más secreta. En este sentido, se puede decir que es comparativa, tal como Goethe había puesto en práctica, apenas unos años antes, con ocasión de sus estudios sobre anatomía comparada en la década de los ochenta y su descubrimiento del hueso intermaxilar (Goethe, 1997: 242). De ahí que la forma de exposición propia de la morfología sean las series. El valor o la utilidad que tiene dicha forma de exposición es que permite al investigador tener una «visión de conjunto» del fenómeno estudiado.

c) La morfología, más que analítica, es sintética, pues la capacidad de síntesis produce y disuelve imágenes y las ordena de forma unitaria ${ }^{10}$.

d) La morfología trabaja con una comprensión fuerte de derivación, entendida no como sucesión deductiva y cuantitativa de las matemáticas, sino como el mismo proceso sucesivo que va de una forma a otra en una gradación cualitativa de fenómenos producida o configurada por una relación de orden móvil: "no me detengo hasta que no encuentro un punto rico en contenido del que muchas cosas se pueden derivar, o más bien que las produzca espontáneamente de sí mismo y me las ofrezca, de modo que yo, en el esforzarme y en el recibir, procedo con cautela y fidelidad» (Goethe, 1997: 215).

Junto a la vertiente metodológica y heurística de esta ciencia general de las formas, cuya reflexión empezó a fraguarse desde 1796 en diálogo con Schiller, el estudio comparativo de las estructuras orgánicas visibles se nutrió también, al mismo tiempo, de un rico trasfondo de orden epistemológico. La pregunta acerca de la visibilidad de esas estructuras nunca estuvo desligada, en efecto, de una cuidadosa preocupación por reivindicar aquellas facultades cognoscitivas que mantuviesen abierta la diversidad de la experiencia y la inteligibilidad como pluralidad fenoménica. La morfología apuntaba, pues, a un problema del conocimiento cardinal, donde ciertamente la intuición (Anschauung) goetheana reivindicó una importante carta de ciudadanía ${ }^{11}$. A fin de cuentas, ella habilitaba la representación ejemplar de los términos sucesivos de una serie temporal dada, que permite unificar la complejidad de un proceso y comprender un objeto dado en la experiencia a la luz de su desarrollo evolutivo, recurriendo para ello a facultades auxiliares como la empatía o la imaginación, tan imprescindibles en el proceder metodológico de Goethe, tanto en su producción poética como aquí científica. Expongamos brevemente el lugar y valor epistemológico de ambas facultades humanas dentro de la propuesta goetheana.

Respecto de la empatía, conviene recordar que una de las definiciones programáticas que Goethe utiliza 
para describir su propio método es la de una «tierna empiría» (zarte Empirie), una máxima que acentúa la vida intrínsecamente relacional y comunicativa de la planta ${ }^{12}$, que la percibe en cierto modo desde su fragilidad como sujeto, personalizándola e incluso humanizándola, a través de su propia manera de ser y de devenir en el mundo natural. Como autoexigencia del observador de la naturaleza, esta definición remite, por un lado, al esfuerzo por comprender el significado de un fenómeno a través de un mirar prolongado, delicado y atento fundamentado en la experiencia directa, de suerte que el sujeto cognoscente llegue a sentirse como "en casa» con el fenómeno estudiado, entendiéndolo con mayor empatía, cuidado y respeto. Por el otro, la clave de este método reside en que permite la emergencia de significados afectivos y cualitativos al mismo tiempo que contenidos empíricos y sensibles, promoviendo un modo de interacción emocional entre el ser humano y el medio ambiente que exige reciprocidad, gratitud $y$ capacidad de asombro ${ }^{13}$. Nos obliga, en definitiva, a rendir cuentas sobre la acción emocional que el mundo natural circundante ejerce sobre nuestra sensibilidad, visualizando con ello una experiencia radicalmente humana de la naturaleza en la naturaleza. También aquí, el camino formativo del observador de la naturaleza no puede desvincularse de una cierta experiencia poética de la vida, de ahí que la analogía con el arte se reafirmara perfectamente en la bella elegía La metamorfosis de las plantas, de 1798, donde el poema didáctico permitía representar la misma experiencia de observación desde dos órdenes simbólicos distintos pero siempre convergentes ${ }^{14}$.

En la medida en que la zarte Empirie aboga por una relación participativa y mutuamente transformadora entre el sujeto cognoscente y la naturaleza, no es del todo casual que la función epistemológica de la imaginación (Einbildungskraft) suponga para Goethe un momento creativo y productor, espontáneamente generativo, que no deba reducirse solo al ámbito estrictamente artístico. Pues al margen de las importantes diferencias que establece como poeta-de manera muy kantiana, dicho sea de paso-, entre imaginación reproductiva y productiva ${ }^{15}$, lo decisivo en este contexto es que el pensamiento morfológico no puede ni debe renunciar al carácter dinámico y flexible de aquella facultad humana que media, en su función transcendental, entre la intuición y el concepto, con una libertad tal que genera la fantasía creativa, la fuerza poético-creadora. Al incorporar la imaginación, el pensamiento morfológico implica siempre también un irrenunciable momento constructivo y poético, que comprende que la propia representación procesual de la naturaleza, su constante formación y transformación generativas, solo puede imaginarse desde la apertura hacia el fenómeno observado y su pluridimensionalidad, desde su cuidadosa visión y escucha, y ya no desde la clausura científica de una representación cerrada y estática que niega la posibilidad de describirse como despliegue móvil de formas de vida en la naturaleza. De ahí que la proyección de imágenes concatenadas en serie sea el modo eminente de representar, de manera sensible, algo que no es directamente accesible a los sentidos, el modo ejemplar en que las relaciones externas entre fenómenos puedan ser imaginadas, por ejemplo, desde la identificación de sus semejanzas estructurales, sus conexiones fácticas o relaciones de sucesión dentro de una ininterrumpida cadena explicativa siempre provisional, garantizando así que la explicación de los fenómenos nunca esté desvinculada de su significado.

\section{LA DEFENSA DE UNA CIENCIA COMO EXPERIENCIA VIVA DE LOS FENÓMENOS}

De lo sostenido hasta el momento, difícilmente podamos equivocarnos demasiado si ahora afirmamos, con cierta solemnidad filosófica, que Goethe nos lleva hacia una ciencia de la experiencia viva de los fenómenos. Las ciencias son, en palabras suyas, «propiamente compendios de vida: son ellas quienes prestan cohesión a las experiencias externas e internas, en general» (FA I, 10: 757). Sin embargo, para la ciencia de filiación newtoniana, como bien supo Kant, la naturaleza es objeto de una experiencia que solo se alcanza idealmente al precio de aislar y dividir los fenómenos retrotrayéndolos a un núcleo matemático-formal, pues solo este es susceptible de ser expresado lingüísticamente mediante aquellas leyes universales que permiten su tratamiento cuantitativo. Con ello olvidamos la presencia fáctica y visible en la que se ofrecen las cosas, acentuando la alienación del cuerpo vivido respecto del mundo circundante y relegando a un segundo plano algo de lo que Goethe en modo alguno quiso prescindir ni en sus investigaciones científicas ni en su labor poética: la inmediatez de lo dado sensiblemente, inmediatez tanto de la presencia física del objeto aprehendido, como de su aprehensión por parte del sujeto observante. Frente a «los innumerables intentos que se hacen en las ciencias para sistematizar y esquematizar», el poeta aboga por que «toda nuestra atención debe dirigirse a percibir el proceder de la naturaleza, no a someterla con prescripciones constrictivas, sino, al contrario, a no dejarnos alejar de la meta a causa de las arbitrariedades» (Goethe, 1997: 210). 
La pobreza gnoseológica que se le imputa a la escisión sujeto-objeto en las ciencias de la naturaleza ciertamente corresponde al ethos especulativo de una época de enorme creatividad, penetración y transversalidad interdisciplinares en el espacio cultural alemán. Del mismo modo que los biólogos identificados con la Naturphilosophie romántica (Kielmeyer, Spix, Oken, Carus) no renunciaron a hipótesis metafísicas para desarrollar nociones como las de analogía, polaridad, totalidad orgánica, etc., tampoco los grandes filósofos del idealismo alemán se desentendieron de los avances positivos en ramas particulares, desde la química hasta la biología (baste pensar en la riqueza epistémica del primer Schelling, pero también en el Hegel de la segunda parte de la Enzyklopädie der philosophischen Wissenschaften). En todo caso, igual que muchos de los jóvenes románticos como Novalis y los hermanos Schlegel, Goethe no ocultó una actitud de cierta provocación frente a las ciencias exactas de la naturaleza, incluidas las matemáticas ${ }^{16}$, presentando su propia alternativa como cultivo de un saber que no se constituye en un ámbito separado y aislado experimentalmente respecto de la experiencia vital e histórica del indagador. En la medida en que todo conocimiento científico se inserta también en la historia personal de los individuos y la acción colectiva de las comunidades humanas, «el conflicto del individuo con la experiencia inmediata y con la tradición mediata es, en realidad, la historia de las ciencias» (HA, 14: 51). De forma harto ambigua, pues, la propia consolidación institucional y académica de las ciencias o incluso el aumento de su prestigio social empezaban a consolidar, por ejemplo, en la transición epistémica de Linneo y Cuvier, el olvido de esa fenomenalidad intermedia constituida desde el observador de la naturaleza.

Por tanto, Goethe no renuncia todavía a encontrar el modo de que en toda ciencia explicación y significado, teoría y praxis no estén disociados; de que la ciencia sea un saber humano de la armonía de la naturaleza que se configure, siguiendo la metáfora musical, al unísono con el ritmo eterno de la vida. La naturaleza no es un conjunto de elementos aislados que puedan ser sometidos pasivamente por un omnipotente sujeto de conocimiento, sino un todo que se expresa en sus partes y que contiene su estructura más propia en su dinámica, en su incesante devenir. De ahí la necesidad de operar con otra noción de teoría, volviendo en cierto modo a su sentido originario como theoreîn, como forma de "mirar», "contemplar» las cosas divinas. Pues como señalará de manera programática, «todo contemplar pasa a ser un considerar; todo considerar, un percatarse; todo percatarse, un entrar en conexión; y así cabe decir que nosotros teorizamos cada vez que lanzamos una mirada atenta al mundo", célebres palabras de la introducción a su Farbenlehre (HA, XIII: 317). Pero también un contemplar como captación de lo divino -un gesto característico de la religiosidad pagana de Goethe-, porque es a través de ella como se reactualiza la hipótesis spinozista de la libertad de la naturaleza ${ }^{17}$, comprendida intuitivamente en su originaria productividad creadora interna, como natura naturans. En la visión divina (theoría) de producirse, nos amoldamos a la naturaleza y podemos participar así en su crearse, contemplarla como copartícipes en su creación multiplicadora y metamórfica en cuanto formas vivas. Y es en la intuición participante de esta naturaleza donde el ser humano desarrolla su libertad y sus posibilidades de creatividad espiritual, tal como se revela análogamente en la experiencia de la creación artística. Allí, en efecto, no se pretende imitar sin más a la naturaleza, ni copiar o reproducir directamente aquello que solo creemos ver con los ojos, sino que el artista aspira a adaptarse primero a la naturaleza, retrocediendo hacia aquella racionalidad donde ella opera y se expresa en su potencialidad más propia y libre. Así comprendido, el artista no tomaría como modelo las cosas u objetos de la naturaleza, pero sí la naturaleza de las cosas, la fuerza creativa del mundo.

Desde este trasfondo, convendría detenerse un poco más en la propia alternativa goetheana, a saber, la comprensión de una genuina teoría viva de las formas naturales. Para ello podría tomarse como punto de partida la célebre afirmación según la cual «lo más elevado sería comprender que los hechos son ya teoría [...] No se busque nada más allá de los fenómenos: ellos mismos son ya la teoría» (HA, XII: 432). De entrada, se entendería mal su dictum si se creyera que lo que Goethe dice aquí es que los fenómenos sustituyen en la teoría a las fórmulas y a los conceptos, así como a los procedimientos e instrumentos propiamente científicos que tal lenguaje ha incorporado para constituir su correspondiente espacio del saber. Lo que trata de decir es que la teoría debe reflejar el orden dinámico de los fenómenos, configurarlo como tal orden, pero teniendo en cuenta, como dirá más adelante, que «ningún fenómeno se explica por y en sí mismo, sino que muchos, considerados juntos, ordenados metódicamente, dan lo que podría llamarse teoría» (HA, XII: 434).

Por tanto, a diferencia del enfoque theory-centered del paradigma newtoniano, Goethe nos propone hacer de los fenómenos y de sus maneras de aparecer el corazón mismo de la ciencia. Su apuesta en cierto 
modo filosófica, que Schiller llegó a definir en términos de "empirismo racional» (rationelle Empirism) ${ }^{18}$, explora e incorpora a las ciencias de su época la variedad de modalidades dinámicas en que un fenómeno puede ser experimentado y conceptualizado, aquello que él Ilama Vorstellungsarten, cuya mediación habilita la relación entre el sujeto cognoscente y la naturaleza a través del juicio intuitivo (anschauende Urteilskraft ${ }^{19}$. Desde tal enfoque epistemológico es comprensible que, para el poeta alemán, el objetivo principal de las ciencias naturales ya no pueda ser el de establecer la verdad de una hipótesis, la validez de una ley cualquiera o la consistencia de un experimentum crucis, sino más bien el de aspirar a una fidelidad en la propia manera de mirar la multiplicidad de los fenómenos dados, tal como se expresan en cada dimensión fenoménica. La naturaleza de la realidad emergería con ello, a través de una experiencia fidedigna de la realidad en cuanto proceso dinámico y transformador en el que nosotros coparticipamos con mayor reflexividad. $\mathrm{O}$ en palabras de Goethe:

Mi pensamiento trabaja objetivamente. Con esto quiero decir que mi pensamiento no se separa de los objetos, sino que los elementos de los objetos, sus imágenes sensibles, confluyen en él y son íntimamente penetradas por él; que mi ver es ya un pensar y mi pensar un ver (Goethe, 1997: 211) ${ }^{20}$.

La ambigua potencialidad y valencia del ojo no es casual en este contexto. Harmut Böhme, por ejemplo, ha definido la ciencia goetheana como una suerte de "fenomenología de la visibilidad» (Phänomenologie der Sichtbarkeit), que buscaría garantizar la integridad tanto de la naturaleza como la del propio cuerpo humano, evitando toda violencia sobre la naturaleza al tiempo que el ser humano aprende a verse reflexivamente en el contexto vivo de la naturaleza (Böhme, 2016: 330). De este modo, la profundidad gnoseológica de un ver que no es un mero mirar invita a pensar un concepto de intuición que no es solo una producción y donación unilaterales de un determinado fenómeno por parte del sujeto en el acto de conocimiento, sino también siempre un darse, un ponerse del objeto a la propia mirada subjetiva de quien lo busca captar intencionalmente. Esta comprensión dinámica de la intuición alberga, desde luego, un potencial críticoconstructivo nada desdeñable, no solo porque mantiene abierto lo fenoménico e impide la mortificación por parte de lo que se pretende definitivamente objetivo, sino también porque defiende la posibilidad de comprender, en la propia intuición de la naturaleza, la intuición del propio pensamiento humano.

\section{LA REFLEXIÓN SOBRE LOS LÍMITES DEL CIENTÍFICO: SU METAMORFOSIS}

Al hilo de esta última reflexión, conviene insistir en que Goethe no se sintió tanto Naturwissenschaftler cuanto Naturforscher, pues no quiso vencer ni dominar la naturaleza, ni tampoco someterla a un conjunto ordenado de leyes inteligibles (por ejemplo, del entendimiento) ${ }^{21}$, sino contemplar la fuerza, los impulsos y el despliegue ubique de la naturaleza misma. Es decir, no experimentación, sino ante todo experiencia humana de la naturaleza ${ }^{22}$. En esa experiencia el magisterio goetheano sigue teniendo plena vigencia y actualidad, precisamente porque sus textos abren a la posibilidad de comprender no solo la metamorfosis de las formas naturales en general, sino de plantear también, en aquellos niveles más propios de la sociología del conocimiento o de la filosofía de la ciencia, la metamorfosis del científico, del investigador o indagador de la naturaleza, como condición de posibilidad para articular otra relación hombre-naturaleza.

Desde los parámetros goetheanos, conviene fijar de entrada que la agonalidad de nuestra relación con la naturaleza no es sino el reverso de la propia mirada antropológica que desconoce la contingencia de todo lenguaje (científico o no), su imposibilidad como representación verdadera, su carácter de mediación históricamente condicionada entre la forma de representación (espíritu) y el fenómeno (naturaleza), tal como se juega en la relación de los sujetos concretos y la naturaleza. Por tanto, la problematicidad epistemológica de un lenguaje científico que no se sabe perspectiva radica, para Goethe, en ignorar que «el conflicto del individuo con la experiencia inmediata y la tradición mediata es, en realidad, la historia de las ciencias» (LA II, 6: 87). De ahí que el progreso en la ciencia, en el sentido defendido en sus numerosos escritos, implique siempre una transformación de nosotros mismos, puesto que «si queremos alcanzar una intuición viviente de la naturaleza, tenemos que mantenernos flexibles y en movimiento, según el ejemplo mismo que ella nos da» (Goethe, 1997: 7). Es decir, depende de nosotros el adaptarnos a lo que los fenómenos tienen que ofrecernos, y no adaptarlos a ellos a nuestro modo de aprehenderlos. Implica, en otras palabras, una transformación consciente de la propia actividad cognitiva, del desarrollo de capacidades y sensibilidades internas, y no solo en términos de refinamiento de instrumentos, procedimientos o métodos externos de observación. Sin ir más lejos, tal era el sentido último de la llamada «fantasía sensible exacta» (Goethe, 1997: 219) que, lejos de ser una 
mera imaginación fantasiosa y romántica, se refiere a una forma de cognición que debemos primero desarrollar a partir del propio trabajo del investigador con el material de la experiencia.

Por un lado, la metamorfosis del científico es un desiderátum metodológico, de talante procedimental o heurístico. Por el otro, reviste también aquella centralidad fundamentalmente epistemológica sin la cual no acabaríamos de situar la radicalidad de la propuesta morfológica de Goethe. Pues cuando asistimos al despliegue simultáneo de la intuitiva mirada descriptiva, clasificatoria, comparativa y legislativa sobre la metamorfosis de las plantas asistimos, en última instancia, al descubrimiento reflexivo, reflejado en la propia performatividad de la escritura científica, según el cual la descripción del yo que investiga se convierte también en la propia representación de la teoría. O dicho de otro modo: en sus ensayos científico-naturales, Goethe no se limita nunca a describir solo la naturaleza, sino sobre todo a visualizar la naturaleza de sus observadores, su escenificación en la primera. Puesto que el método científico no puede jamás desligarse del sujeto corporeizado, sino, antes bien, debe incluir la experiencia corporeizada como parte integral de la indagación científica, la educación en cierto modo estética de nuestra sensibilidad con respecto al mundo natural circundante solo es pensable desde una flexibilidad lo suficientemente creativa y abierta para adecuarse a la dinámica ontogenética de la historia de la naturaleza, de sus formas de vida y sus temporalidades.

Reactualizar este horizonte de comprensión desde nuestros parámetros actuales no es tarea fácil. La moderna renuncia de los individuos a la responsabilidad de su percepción de la naturaleza ha afectado negativamente a la forma en que toda nuestra cultura se relaciona con el mundo natural, de ahí que esfuerzos como los de Goethe a la hora de pensar una ciencia de la naturaleza que saliera al paso del reduccionismo mecanicista, a sus premisas ontológicas y marcos epistemológicos, a sus metáforas y dualismos metafísicos, a su metodología analítico-disociadora revelen todavía hoy una destacable potencialidad teórica. Puesto que la cuestión en juego no es simplemente la degradación de la naturaleza, sino la degradación de nuestra conciencia de la naturaleza, considero que el llamado "delicado empirismo" de Goethe y la metodología desarrollada al respecto pueden ayudarnos a reintegrar modalidades de un saber comprensivo orientado más hacia el proceso, más holístico, copartícipe y corresponsable del mundo que comparte como naturaleza. La pregunta que debemos hacernos, por tanto, es la siguiente: ¿se está trasladando nuestra habilidad para predecir, controlar y manipular los procesos naturales hacia la mejora de nuestra habilidad de hacer inteligibles las complejas dinámicas e interrelaciones en las formas de vida de la naturaleza? De la respuesta a esta pregunta depende ciertamente el encaje de la propuesta goetheana, cuya mirada científica, responsable y creativa, nos enseña a participar de manera activa en un proceso en el que la naturaleza y la naturaleza del hombre se observan y se experimentan a sí mismas.

\section{AGRADECIMIENTOS}

El autor quisiera agradecer la valiosa lectura realizada por Javier Gálvez Aguirre, cuyos comentarios y sugerencias han contribuido a mejorar tanto la redacción como la estructura del manuscrito.

\section{NOTAS}

1. De entre la importante bibliografía disponible, destacaré algunos de los trabajos que me han acompañado a lo largo de esta indagación, sobre todo Amrine, Zucker y Wheeler (1987), Sánchez Meca (1998), Schieren (1998), Seamon y Zajonc (1998), Steuer (1999), Duque (2000), Richards (2002), Möckel (2003), Mas (2004), Fischer y Nassar (2005), Meyer-Abich (2005), Breidbach (2008), Heusser (2008), Wunenburger (2011), Riegner (2013), Holdrege (2014), Grave (2014) y Maatsch (2014).

2. Salvo que se señale de manera expresa, citaré por la edición en castellano de los principales escritos científico-naturales de Goethe (1997). Para otros textos, y debido a dificultades de consulta y acceso, citaré según la convención académica y de manera alternativa tanto por la Hamburger Ausgabe [HA] como por la Leopoldina [LA], indicando a continuación el volumen y la página correspondiente.

3. Imprescindible el capítulo de la obra de Richards dedicado a Blumenbach y a la posterior reformulación kantiana $y$ goetheana del concepto de Bildungstrieb, es decir, del impulso o pulsión formativos (Richards, 2002: 207-229).

4. Como es sabido, esta dinámica decisiva entre Polarität y Steigerung, a la que no podemos aludir sino de pasada, será clave también para la futura
Farbenlehre. Remito para esta cuestión al capítulo segundo del excelente trabajo de Arnaldo (2019).

5. Justo aquí se advierte la conexión entre la Urpflanze y el llamado Urphänomen o "fenómeno originario», es decir, aquella estructura cardinal estudiada con ocasión de su teoría de los colores, a partir de la cual se podrían deducir otros muchos fenómenos cromáticos. Si el Urphänomen, en cuanto síntesis entre lo ideal y lo real, entre lo inteligible y lo sensible, establece la razón natural en su universalidad dinámica, la metamorfosis la instituye en su concreción como variación singular tanto en el espacio de las formas de vida natu- 
rales como también en el tiempo específicamente cíclico de la naturaleza. Tal esencia goetheana no es por tanto una forma o estructura ideales a la manera platónica, sino un poder de estructuración, es decir, de incesante formación y perfeccionamiento continuo (Bildung).

6. Un Proteo en cuya transfiguración parece latir la vida intelectual de un «Diosnaturaleza». En su particular respuesta a la vieja problemática -reavivada por Leibniz- del paso de lo uno a lo múltiple, la planta modelo reafirmaba ciertamente el particular spinozismo de Goethe (Meyer-Abich, 2005), intensificado desde el invierno de 1784/85 en diálogo con Jacobi y sobre todo con Herder. Pero el traslado de su particular panteísmo y su comprensión de la naturaleza como unidad de materia y espíritu, y en general su deuda con la scientia intuitiva spinozista y su confianza en el conocimiento de la divinidad a través del conocimiento de la naturaleza, siempre se cifró en el estudio de las rebus singularibus. Recordemos, a este respecto, la carta a Jacobi del 9 de junio de 1785 y la del 5 de mayo de 1786 (HaBr. 1: 456 y 508 ss.).

7. Para esta cuestión, remito a la excelente exposición de Lacoste (1997: 42-79).

8. Por otro lado, esta morfología no es un saber de las causas, sino una descripción de «las condiciones bajo las cuales los fenómenos aparecen, se contempla y se acepta su sucesión coherente, su eterno retorno bajo mil circunstancias diversas, su unicidad y mutabilidad; se reconoce su determinación y se la determina de nuevo mediante el espíritu humano» (Goethe, 1997: 175).

9. Como recuerda acertadamente Sánchez Meca, la perspectiva de Goethe supone «una comprensión de la historia a partir de la naturaleza y no una comprensión del mundo a partir de la historia» (Sánchez Meca, 1998: 61).

10. Goethe nos recuerda aquí la deuda contraída con la primera Crítica kantiana para dar un impulso teórico decisivo a su morfología: "Estaba de acuerdo también con los conocimientos a priori, así como con los juicios sintéticos $a$ priori, pues en toda mi vida, en la poesía como en la investigación científica, había procedido siempre sintéticamente y después analíticamente; la sístole y la diástole del espíritu humano era para mí casi como una segunda respiración, jamás separada sino siempre impul- sante. Pero no tenía palabras para todo esto, y menos aún frases. Ahora, por primera vez, parecía que una teoría me ayudaría» (Goethe, 1997: 181). Sobre la influencia de Kant en Goethe, remitimos a Förster (2002) y Mas (2004).

11. Respecto de la lebendige Anschauung remitimos a Schieren (1998: 198-210) y Möckel (2003: 25-36).

12. No en vano la perspectiva biosemiótica, que defiende que el lenguaje humano no debe ser la única forma del proceso comunicativo, ha encontrado en Goethe un gran aliado. Por un lado, su mirada simultáneamente artística y científica fomenta una escuela de la sensibilidad, donde los organismos vivos son signos dotados de sentido no solo para los seres humanos, sino que ellos mismos están envueltos en distintos procesos de comunicación (semiosis) que, según Rigby (2005: 24), son «intrínsecos a la existencia y a la interacción de todos los organismos vivos (bios)». Por otro lado, Goethe defiende una concepción expansiva del lenguaje científico, inseparable de las cualidades del decir poético, restaurando la agencia comunicativa entre seres vivos no humanos, para expandir y enriquecer también nuestra comprensión de las relaciones de signos humanos.

13. Conviene recordar que el asombro constituye también un elemento decisivo dentro de la epistemología goetheana, en un sentido parecido al thaumázein griego, aunque incide incluso con mayor radicalidad, al integrarse en la mezcla de tradiciones neoplatónicas, herméticas y spinozistas del joven Stürmer que le enseñó muy pronto a valorar el profundo respeto, la Ehrfurcht hacia el secreto revelado de cuanto vive. Como señala van Eynde «El naturalista goetheano debe conocer la Scheu, es decir, la angustia comprometida de respeto frente a la manifestación natural. La creencia respetuosa, en la medida en que preserva la transcendencia que se ajusta a la manifestación misma de la naturaleza, no es anticipada, sino que permanece abierta a lo que vaya a surgir, y acepta, en este sentido, ser sorprendida por la invención de la naturaleza» (van Eynde, 2011: 24).

14. Un convincente análisis de este poema lo firma Lacoste (1997: 15-21).

15. Diferencias analizadas con rigor por Mas (2004: 366 y ss.).
16. Más allá de la incansable polémica con Newton en su teoría de los colores, basta pensar en las reflexiones, no exentas de dureza, dirigidas a las matemáticas en general, por ejemplo, en "Sobre la matemática y su abuso» (Goethe, 1997: 220-235). En la medida en que, como seres humanos relacionados con el mundo circundante, nuestra experiencia real es la de las cualidades, no la de los números ni la de las fórmulas matemáticas, la modalidad cuantitativa del lenguaje matemático aplicado a los fenómenos vivos de la naturaleza revela, al decir de Cassirer, una impotencia y disfuncionalidad descriptivas para pensar las formas orgánicas, no como "formas dentro del espacio, sino en formas del tiempo" (Cassirer, 1948: 182). Sobre la lectura de Goethe realizada por el último Cassirer debe consultarse también la última parte de Rousseau, Kant, Goethe (Cassirer, 2007: 233-279).

17. Para Goethe, habilitar el «camino libre de la naturaleza» (LA I, 3: 154) implicó un veto parcial pero contundente a la reducción de la libertad a monopolio exclusivamente humano. Afirmar la libertad de la naturaleza, incluso pensarla como portadora de determinados derechos, debía evitar posiciones sintomáticas como las que creía observar en el idealismo de Schiller, más dependiente da la dinámica antinómica entre libertad y necesidad planteada por Kant (Kant, 2016: 407). A fin de cuentas, en la medida en que concebía la naturaleza en términos de libertad, en una filiación ciertamente más spinozista, Goethe se negaba a hacer empezar el reino de la libertad allí donde terminaba el de la naturaleza, actitud que sin duda había querido ver reflejada en su amigo: «Él [Schiller] predicaba el evangelio de la libertad, y yo no quería que menoscabaran los derechos de la naturaleza» (Goethe, 1997: 184).

18. Como explica a Schiller en la carta del 21 de febrero de 1798 «[El empirismo racional] permite que coexistan ciertas formas de representación mental y no se atreve a excluir alguna o expandir el ámbito de una hacia el de otra» (Goethe y Schiller, 2014: 308).

19. La influencia de la tercera Crítica kantiana (Kant, 2012) es aquí decisiva por iluminar con argumentos concluyentes la isonomía entre ciencia y arte, por tanto, la mutua penetración entre juicio teleológico y juicio estético. Véase «Influencia de la nueva filosofía» 
(Goethe, 1997: 182 y ss.). Para una mayor profundización remitimos a Hurson (2000) y Mas (2004), así como al clásico trabajo de Förster (2002). El juicio intuitivo goetheano asume así, en líneas generales, las características del juicio estético kantiano, naturalizándolo. Las formas surgen, desde esta perspectiva, por una acción espontánea de la naturaleza, y no están sujetas a ninguna ley

\section{REFERENCIAS}

Amrine, Frederick; Zucker, Francis J. y Wheeler, Harvey (eds.) (1987). Goethe and the Sciences: A Reappraisal. Boston: Kluwer Academic Publishers. https:// doi.org/10.1007/978-94-009-3761-1

Arnaldo Alcubilla, Javier (2019). Vemos lo que sabemos: la cultura de la visión en Goethe. Madrid: Abada.

Böhme, Hartmut (2016). Natur und Figur: Goethe im Kontext. Paderborn: Wilhelm Fink Verlag. https://doi. org/10.30965/9783846760468

Breidbach, Olaf (2008). Gedanken zu Goethes Metamorphosenlehre. Goethe-Jahrbuch, 125: 95-109.

Cassirer, Ernst (1948). La idea de la metamorfosis y la 'morfología idealista'. En: Ernst Cassirer. El problema del conocimiento IV. De la muerte de Hegel a nuestros días 1832-1932. México: Fondo de Cultura Económica, pp. 171-185.

Cassirer, Ernst (2007). Rousseau, Kant, Goethe. Filosofía y cultura en la Europa del Siglo de las Luces. México: Fondo de Cultura Económica.

Duque, Félix (2000). 'Alles ist sie mit einem Male'. La actitud de Goethe en la naturaleza. Estudi general: Revista de la Facultat de Lletres de la Universitat de Girona, 19: 83-104.

Eynde, Laurent van (2011). En quoi la $\mathrm{Na}$ turphilosophie est-elle proprement philosophique? En: Lequan, Mai (ed.). Goethe et la Naturphilosophie. Paris: Klincksieck, pp. 15-32.

Fischer, Luke y Nassar, Dalia (2005). Introduction: Goethe and Environmentalism. Goethe-Yearbook, XXII: 3-22. https:// doi.org/10.1353/gyr.2015.0032

Förster, Eckart (2002). Die Bedeutung von $\S \S 76,77$ der 'Kritik der Urteilskraft' für die Entwicklung der nachkantischen Philosophie [Teil 1]. Zeitschrift de finalidad, a ninguna teleología que fundamente el conocimiento específico de las entidades orgánicas.

20. Como señala en otro pasaje: «Puede haber una diferencia entre ver y ver, que los ojos del espíritu y los ojos del cuerpo deben actuar en una constante y viviente conexión, porque de otro modo se corre el peligro de mirar y, sin embargo, no captar lo que se ve» (Goethe, 1997: 98).

für philosophische Forschung, 56 (2): 169-190.

Goethe, Johann Wolfgang (1955-1971). Werke. Hamburger Ausgabe in 14 Bänden [HA]. Hamburg: Christian Wegner.

Goethe, Johann Wolfgang (1988). Goethes Briefe in 4 Bänden (Hamburger Ausgabe $[\mathrm{HaBr}])$. Karl Robert Mandelkow (ed.). München: C. H. Beck.

Goethe, Johann Wolfgang (1991). Viajes italianos. En Obras completas, III. Madrid: Aguilar.

Goethe, Johann Wolfgang (1997). Teoría de la naturaleza. Madrid: Tecnos.

Goethe, Johann Wolfgang y Schiller, Friedrich (2014). "La más indisoluble unión». Epistolario completo 1794-1805. Marcelo G. Burello y Regula Rohland de Langbehn (eds.). Buenos Aires: Miño y Dávila.

Grave, Johannes (2014). 'Beweglich und bildsam': Morphologie als implizite Bildtheorie? En: Maatsch, Jonas (ed.). Morphologie und Moderne. Goethes 'anschauliches Denken' in den Geistes- und Kulturwissenschaften. Berlin/Boston: Walter de Gruyter, pp. 57-74. https:// doi.org/10.1515/9783110368673.57

Heusser, Peter (2008). Goethes Verständnis von Naturwissenschaft. Goethe-Jahrbuch, 125: 110-121.

Holdrege, Craig (2014). Goethe and the Evolution of Science. In Context, 31: 10-23.

Hurson, Didier (2000). Goethe, interprète et critique de Kant. En: Jean-Marie Valentin (ed.). Johann Wolfgang Goethe. L'Un, l'Autre et le Tout. Paris: Klincksieck, pp. 549-566.

Kant, Immanuel (2016). Crítica de la razón pura. Madrid: Taurus.

Kant, Immanuel (2012). Crítica del discernimiento (o de la facultad de juzgar). Madrid: Alianza.
21. «El entendimiento no puede pensar unificado lo que la sensibilidad le transmite de manera separada y así queda por siempre sin solución el conflicto entre lo aprehendido y lo ideado» (Goethe, 1997: 191).

22. Iluminador resulta aquí el texto «El experimento como mediador entre objeto y sujeto» (Goethe, 1997: 157-158).

Lacoste, Jean (1997). Goethe. Science et philosophie. Paris: Presses Universitaires de France.

Maatsch, Jonas (2014). Morphologie und Moderne. Zur Einleitung. En: Jonas Maatsch (ed.). Morphologie und Moderne. Goethes 'anschauliches Denken' in den Geistes- und Kulturwissenschaften. Berlin/Boston: Walter de Gruyter, pp. 1-15. https://doi.org/10.1515/9783110368673

Mas, Salvador (2004). Goethe y Kant: arte, naturaleza, ciencia. Éndoxa. Series filosóficas, 18: 355-382. https://doi. org/10.5944/endoxa.18.2004.5095

Meyer-Abich, Klaus Michael (2005). Libertà nella natura: il congeniale spinozismo di Goethe. En: Gian Franco Frigo, Raffaella Simili, Federico Vercellone y Dietrich von Engelhardt (eds.). Arte, scienza e natura in Goethe. Torino: Trauben, pp. 269-291.

Möckel, Christian (2003). Anschaulichkeit des Wissens und kulturelle Sinnstiftung. Beiträge aus Lebensphilosophie und symbolischen Idealismus zu einer Goetheschen Fragestellung. Berlin: Logos Verlag.

Richards, Robert J. (2002). The Romantic Conception of Life. Science and Philosophy in the Age of Goethe. Chicago/ London: The University of Chicago Press. https://doi.org/10.7208/chicago/9780226712185.001.0001

Riegner, Mark F. (2013). Ancestor of the new archetypal biology: Goethe's dynamic typology as a model for contemporary evolutionary developmental biology. Studies in History and Philosophy of Biological and Biomedical Sciences, 44: 735-744. https://doi. org/10.1016/j.shpsc.2013.05.019

Rigby, Kate (2005). Art, Nature, and the Poesy of Plants in the Goethezeit: A Biosemiotic Perspective. Goethe Yearbook, XXII (1): 23-44. https://doi.org/10.1353/ gyr.2015.0000 
Sánchez Meca, Diego (1998). Los conceptos griegos de physis y theoria en la interpretación de Goethe. Daimon, 16: 57-71.

Schieren, Jost (1998). Anschauende Urteilskraft: methodische und philosophische Grundlagen von Goethes naturwissenschaftlichem Erkennen. Düsseldorf/ Bonn: Parerga.
Seamon, David y Zajonc, Arthur (eds.) (1998). Goethe's Way of Science. A Phenomenology of Nature. Albany (NY): State University of New York Press.

Steuer, Daniel (1999). Die stillen Grenzen der Theorie. Übergänge zwischen Sprache und Erfahrung bei Goethe und Wittgenstein. Köln/Weimar/Wien: Böhlau.
Wunenburger, Jean-Jacques (2011). Goethe, notes sur une épistémologie alternative: forme, image et vision. En: Mai Lequan (ed.). Goethe et la Naturphilosophie. Paris: Klincksieck, pp. 63-74. 